\title{
Frames semânticos como organizadores do léxico do Direito Processual Penal: uma proposta metodológica
}

\author{
Semantic frames as organizers of the lexicon of the Criminal Procedural Law: a methodological proposal
}

\author{
Rove Chishman
}

Aline Nardes dos Santos

\section{Fernando José Amâncio Rodrigues}

\section{Bruna Colares Rodrigues}

Universidade do Vale do Rio dos Sinos - Unisinos - São Leopoldo - Rio Grande do Sul - Brasil

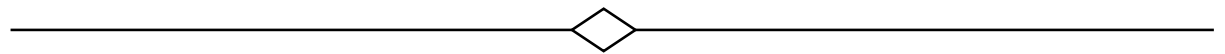

Resumo: O contexto deste artigo é o projeto de criação do Dicionário de Cenários Jurídicos, que está sendo desenvolvido pelo grupo SemanTec/Unisinos. Trata-se de um portal online, voltado a estudantes de Direito e a demais profissionais interessados na área, que visa a descrever o domínio jurídico de forma acessível. Para isso, o projeto tem como base teórico-metodológica a Semântica de Frames. Essa teoria linguístico-cognitiva propõe a descrição do significado por meio de estruturas conceptuais (frames), evocadas pelo léxico, que valorizam o conhecimento experiencial necessário ao entendimento de usos linguísticos - inclusive aqueles voltados a domínios especializados. Com vistas a exemplificar as etapas de descrição do domínio jurídico empregadas, o trabalho explora o processo de descrição de frames das fases Acusatória e Recursal, discutindo os desafios encontrados e as propostas de aprimoramento da metodologia. Os resultados indicam que a organização do domínio jurídico por meio dessa teoria permite a extração sistemática do léxico que caracteriza o Direito Processual Penal. Além disso, destaca-se que o uso de dois diferentes tipos de corpora (processável e não processável) permite uma relação simbiótica entre as contrapartes quali e quantitativa do trabalho, visto que o processo de pesquisa e confirmação das unidades lexicais do domínio investigado, em alguns casos, pode demandar buscas que integrem consultas integradas ao corpus de estudo e ao corpus de apoio.

Palavras-chave: Semântica de Frames, Direito Processual Penal, Frames jurídicos.

Abstract: The context of this paper is the project of creation of the Dictionary of Legal Scenarios, which is being developed by the SemanTec/Unisinos group. It is a website for Law students and other professionals interested in the area, which aims at describing the legal domain in an accessible way. Considering such goals, the project's theoreticalmethodological framework is Frame Semantics. This cognitive-linguistic theory provides a description of meaning through conceptual structures (frames), evoked by the lexicon, that also value the experiential knowledge necessary to the understanding of linguistic uses including those related to specialized domains. With the purpose of exemplifying the description process of the legal domains conducted in this context, the paper explores the process of description of frames from the Charging and Appealing phases, discussing the related challenges and proposals of improvement of the methodology. The results indicate that the organization of the legal domain through this theory allows the systematic extraction of the lexicon that characterizes the Criminal Procedural Law. Moreover, the study highlights that the use of two different types of corpora (processable and nonprocessable) establishes a symbiotic relation between the quali-quantitative counterparts of the research, since the process of collection and acknowledgement of the lexical units of the investigated domain, in some cases, may demand searches that integrate integrated consultations to the study corpus and the support corpus.

Keywords: Frame Semantics, Criminal Procedural Law, Legal frames. 


\section{Introdução}

Este artigo se insere no contexto de pesquisa do Grupo SemanTec, da Universidade do Vale do Rio dos Sinos, cujos projetos se voltam à descrição de domínios especializados na interface entre a Semântica de Frames, a Linguística de Corpus e a Lexicografia Eletrônica. (CHISHMAN, 2016). Na esteira dessas investigações, 0 grupo tem desenvolvido pesquisas que têm como objeto a linguagem jurídica, considerando a relevância da acessibilidade de tal domínio ao público leigo e semileigo. Como afirma Rodrigues (2019, p. 13), constata-se uma grande

[...] dificuldade em tornar o conhecimento especializado na área do Direito acessível às pessoas que se relacionam direta ou indiretamente com as regras jurídicas. E fato também que o domínio do Direito é restrito e dificultoso, o que, por vezes, pode violar o princípio constitucional de acesso à justiça esculpido no artigo $5^{\circ}$ da Constituição da República Federativa do Brasil. (BRASIL, 1988). Ou seja, essa característica acaba por tornar árdua a aproximação entre a justiça e a sociedade.

Mais especificamente, o artigo aborda 0 desenvolvimento do Dicionário de Cenários Jurídicos, projeto em andamento que tem como público-alvo graduandos da área do Direito, além de demais profissionais e pesquisadores que trabalhem na interface com esse campo do conhecimento. Esse recurso lexicográfico será disponibilizado aos usuários no formato de portal eletrônico, organizando o léxico jurídico de acordo com postulados da Semântica de Frames (FILLMORE, 1982; 1985). Tal escolha teórica se justifica pela sua relevância lexicográfica (ATKINS; RUNDELL; SATO, 2003), que tem sido atestada nos projetos desenvolvidos pelo grupo SemanTec voltados a diferentes domínios especializados.

Com vistas a delinear a proposta metodológica que embasa a construção desse recurso, o artigo se estrutura em três seções. $\mathrm{Na}$ seção de fundamentação teórica, abordamos os principais postulados da Semântica de Frames que evidenciam sua pertinência para a descrição da linguagem jurídica. Em seguida, descrevemos o percurso metodológico adotado pelo projeto, incluindo o processo de coleta e compilação de corpora. $\mathrm{Na}$ terceira seção, ilustramos o processo de descrição de cenários jurídicos e discutimos os principais desafios até então encontrados, tendo como ponto de partida a subárea do Direito Processual Penal. Por fim, após abordarmos os resultados até então encontrados, realizamos algumas considerações acerca das perspectivas e dos possíveis desdobramentos de pesquisa que vislumbramos a partir de tal proposta metodológica.

\section{Fundamentação Teórica}

A noção de frame semântico, de modo geral, concerne a "formas estruturadas de se interpretar experiências"1 às quais constantemente recorremos para compreendermos o mundo e interagirmos em sociedade. (FILLMORE, 1976, p. 20). Para o autor, um frame concerne a

[...] qualquer sistema de conceitos relacionados de tal maneira que para entender qualquer um deles é preciso entender a estrutura que os comporta como um todo; quando um dos itens de tal estrutura é introduzido em um texto ou em uma conversa, todos os outros se tornam automaticamente disponíveis. (FILLMORE, 1982, p. 11). ${ }^{2}$

Por exemplo, no campo do Direito, compreender a palavra citar implica conhecer o frame que ela evoca - ou seja, o evento em que um réu recebe um mandado de citação para apresentar sua defesa. Nesse contexto, o frame Citação possui participantes denominados elementos de frame, os quais estruturam o cenário evocado. A imagem a seguir ilustra essa

\footnotetext{
${ }^{1}$ No original: "structured ways of interpreting experiences".

2 "[...] any system of concepts related in such a way that to understand any one of them you have to understand the whole structure in which it fits; when one of the things in such a structure is introduced into a text, or into a conversation, all of the others are automatically made available."
} 
dinâmica entre o frame Citação e seus elementos, colocados entre parênteses, trazendo uma imagem que ilustra o evento em jogo:

Figura 1 - O frame Citação

\section{Frame Citação}

Frame Citação

Este frame corresponde ao Este frame corresponde ao evento em que o réu (Citado) recebe evento em que o réu (Citado) do oficial de justiça (Citante) a comunicação (Mandado de recebe do oficial de justiça Citação) da existência de uma ação judicial em seu desfavor, (Citante) a comunicação devendo, para tanto, apresentar a sua defesa.

(Mandado de Citação) da

existência de uma ação judicial em seu desfavor, devendo, para tanto, apresentar a sua defesa.

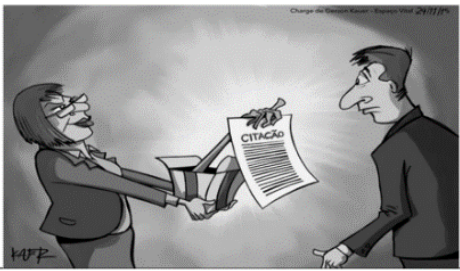

Fonte: Minghelli (2016, p. 155).

Dessa forma, frames derivam de nossa capacidade de categorizar o mundo segundo nossas vivências culturais, de modo que tais estruturas refletem as "continuidades [...] entre linguagem e experiência". (FILLMORE, 1982, p. 111)3. A partir dessa perspectiva, considera-se que a assimilação e a partilha desses novos itens linguísticos refletem operações cognitivas relativas à aprendizagem e à disseminação social de novos frames. (FILLMORE, 1976). A exemplo disso, um estudante de Direito deve apropriar-se de frames jurídicos ao adentrar tal área do conhecimento, com vistas a compreender adequadamente os textos que circulam nesse campo e comunicar-se com seus pares de maneira fluida e competente.

Um dos pilares da Semântica de Frames é a teoria dos protótipos (ROSCH, 1973). Segundo essa abordagem, resultante de estudos em psicologia cognitiva, a capacidade humana de agrupar entidades e objetos em grupos, ou de categorizar, implica a noção de prototipicidade, ou de efeito prototípico. Dessa forma, conforme Rosch (1973), cada categoria possui exemplos mais prototípicos que outros: uma galinha dificilmente é considerada como o melhor exemplo da categoria dos pássaros (GEERAERTS, 2006). Nesse sentido, por meio da compreensão do frame semântico como categoria de experiência que reflete nosso acervo mental de protótipos (FILLMORE, 1976), o qual é dependente de nosso contexto sociocultural, é possível compreender que os frames jurídicos brasileiros refletem a dinâmica do sistema judiciário de nosso país conforme sua prototipicidade, bem como expressam uma cultura especializada que está subordinada à doutrina e à jurisprudência atinentes a esse âmbito. Assim, conforme a própria jurisprudência vai se alterando, certos frames se podem se modificar em função de tais decisões.

Importa pontuar que, em virtude da associação feita por Fillmore entre frames e protótipos e considerando que sua proposta prima pelo estudo do significado, a teoria da Semântica de Frames faz parte do escopo da Linguística Cognitiva, empreendimento que abrange diversas teorias as quais partilham, dentre outros aspectos, de postulados que preconizam uma semântica cognitiva, quais sejam:

a) o principal objetivo dessas teorias é o estudo do significado (KÖVECSES, 2006);

b) nesse contexto, a linguagem é vista como habilidade cognitiva inter-relacionada a outros processos mentais, incluindo nossas "interações no e com nosso ambiente" (JOHNSON, 1987, p. xxxviii), por meio dos quais é possível compreender a produção de significações (SALOMÃO, 2006);

C) o estudo desses processos é baseado na ativação e projeção de domínios cognitivos - dentre eles, os frames (SALOMÃO, 2006);

d) visto que tais estruturas cognitivas são permeadas de experiências não linguísticas, o significado é considerado como fenômeno enciclopédico (LANGACKER, 2008), no sentido de que o conhecimento linguístico é uma porção diminuta desse processo, se comparado à preponderância de atividades que abarcam "experiência sensória, sinestésica e emotiva; reconhecimento do contexto imediato (social, físico e linguístico), dentre outros aspectos" (LANGACKER, 2006, p. 30).

\footnotetext{
${ }^{3}$ No original: "[...] the continuities [...] between language and experience".
} 
Nesse contexto, teorias linguístico-cognitivas como a Semântica de Frames partem do pressuposto de que as formas linguísticas per se não contêm significados, visto que seu uso abre possibilidades de interpretação de acordo com os frames que estão em jogo. Dessa forma, palavras servem como "pista suscitadora das tarefas semântico-cognitivo-sociais da linguagem. Na expressão de Fauconnier (1994:xxii), 'a linguagem não porta o sentido, mas o guia'." (MIRANDA, 2001, p. 61).

No que se refere ao domínio jurídico, salientamos que diversas pesquisas acadêmicas têm apontado a relevância da Semântica de Frames para a descrição da área. Dentre elas, destacamos o trabalho de Pimentel (2012, p. 307), que constatou a relevância da teoria para "descrever as propriedades extralinguísticas de verbos especializados"4. Nessa direção, Minghelli (2016) analisou os eventos legais sob a perspectiva fillmoriana, verificando a necessidade de inclusão das noções de frame e elemento de frame no processo de descrição de eventos legais. Por sua vez, Müller (2015), em um estudo de interface com a computação e a área das ontologias, verificou que a Semântica de Frames permite uma sistematização mais precisa do domínio jurídico, dado que explicita adequadamente a profusão de papéis que os participantes de cada frame podem exercer. Aprofundando essa questão, Rodrigues (2019, p. 113) investigou a dinâmica dos sujeitos processuais na área do Direito Processual Penal, concluindo que

[...] a Semântica de Frames pode contribuir para uma melhor compreensão dos sujeitos processuais no Direito Processual Penal, pois apresenta aplicabilidade e pertinência para a descrição dos sujeitos processuais - não só quanto à identificação e à descrição de tais elementos, mas também quanto à organização dos sujeitos processuais em cada uma das fases que constituem a dinâmica dos atos e procedimentos jurídicos.

Tendo em vista essas contribuições, abordamos os caminhos metodológicos que têm sido adotados na construção do Dicionário de Cenários Jurídicos.

\section{Procedimentos Metodológicos}

Nesta seção, apresentamos os procedimentos utilizados para construir o Dicionário de Cenários Jurídicos, um recurso lexicográfico baseado em frames semânticos. Reiteramos que a descrição aqui abordada se refere ao primeiro recorte estabelecido por nosso grupo de pesquisa, concernente ao Direito Processual Penal, mais especificamente ao Procedimento Comum Ordinário, no qual podem ser impostas condenações às penas restritivas de liberdade com período igual ou superior a 4 anos. (RODRIGUES, 2019). O principal critério para escolha desse subdomínio é a recorrência e a prototipicidade de tal procedimento, em comparação aos procedimentos especiais.

A metodologia inclui a manipulação de dois corpora que apresentam características distintas:

a) corpus de apoio: utilizado para descrição dos frames e sistematização de suas relações em mapas conceituais. Não está em formato processável e constitui-se, nomeadamente, dos seguintes documentos: a Constituição da República Federativa do Brasil; a Lei nº. 3.689/1941b, a qual institui o Código de Processo Penal; e os livros teóricos, denominados de doutrina ou manuais, relativos a diversas áreas do Direito.

b) corpus de estudo: utilizado para confirmação dos frames identificados no corpus anterior. É constituído de acórdãos do Tribunal Regional Federal da 4ª Região, e seu formato é processável por uma ferramenta de análise de corpus. Mais especificamente, o material é manipulado por meio do software Sketch Engine. Desse modo, o corpus de estudo permite-nos realizar observações precisas sobre o real comportamento linguístico (ALUíSIO, 2006, p. 158) dos termos jurídicos no Procedimento Comum Ordinário do Processo Penal.

\footnotetext{
${ }^{4}$ No original: "to describe the extralinguistic properties of specialized verbs".
} 
Seguindo a metodologia de descrição de frames estabelecida por Fillmore e Baker (2010), o trabalho se inicia pelo esboço do respectivo cenário conforme o conhecimento dos pesquisadores. No caso do Direito Processual Penal, como se trata de um âmbito específico que não pode ser descrito sem que se conheça suficientemente a área, estabelecemos uma etapa inicial de estudo do domínio e de criação de mapas conceituais, com auxílio de um especialista em Direito. Nesse processo, são elencadas também as possíveis unidades lexicais que evocam o frame (FILLMORE; BAKER, 2010). A partir desse primeiro mapeamento, passamos a trabalhar com o corpus de estudo, por meio do qual buscamos as unidades lexicais previamente elencadas e observamos suas combinatórias, consolidando então a lista final de evocadores de cada frame. O Quadro 1 sistematiza os procedimentos adotados na exploração dos corpora de apoio e de estudo:

Quadro 1 - O trabalho com os corpora: procedimentos iniciais

\begin{tabular}{|c|c|}
\hline $\begin{array}{l}\text { Metodologia: etapa com o } \\
\text { corpus de apoio }\end{array}$ & $\begin{array}{l}\text { Metodologia: etapa com o } \\
\text { corpus de estudo }\end{array}$ \\
\hline $\begin{array}{l}\text { a) Estudo do domínio e } \\
\text { criação de mapas } \\
\text { conceituais; } \\
\text { b) Confirmação da } \\
\text { descrição com auxílio de } \\
\text { um especialista; } \\
\text { c) Sistematização de de } \\
\text { frames e de suas } \\
\text { relações previamente ao } \\
\text { corpus; } \\
\text { d) Levantamento de } \\
\text { possíveis unidades } \\
\text { lexicais que evocam } \\
\text { frames jurídicos. }\end{array}$ & $\begin{array}{l}\text { a) Busca de termos } \\
\text { previamente elencados, } \\
\text { a partir do estudo de } \\
\text { domínio; } \\
\text { b) Extração de } \\
\text { concordâncias de } \\
\text { exploração } \\
\text { combinatórias; } \\
\text { c) Consolidação da lista } \\
\text { de unidades lexicais e } \\
\text { dos frames, de acordo } \\
\text { com os dados } \\
\text { analisados. }\end{array}$ \\
\hline
\end{tabular}

Fonte: Elaborado pelos autores.

Os procedimentos iniciais expostos no Quadro 1 têm sido aperfeiçoados e revistos conforme os desafios relativos à descrição de frames jurídicos têm surgido. Alguns aspectos atinentes a tal processo de análise são abordados na seção a seguir.

\section{Descrevendo frames jurídicos: exemplos de análise}

Tendo em vista o Procedimento Comum Ordinário como recorte temático, nesta seção, abordamos alguns aspectos atinentes à descrição das fases processuais que compõem 0 referido procedimento por meio de mapas conceituais. Salientamos que, considerando nossa perspectiva interdisciplinar, compreendemos as fases e os atos processuais estabelecidos no campo do Direito segundo a ótica da Semântica de Frames; por conseguinte, as grandes fases ou partes que o compõem são superframes, quais sejam:

a) Fase Investigatória: composta pelos atos prototípicos da investigação policial, reunidos no inquérito policial.

b) Fase Acusatória: inicia-se com o oferecimento da denúncia pelo representante do Ministério Público, que deve indicar o suposto autor e os respectivos fatos.

c) Fase Instrutória: permite às partes envolvidas sustentar ou refutar a denúncia oferecida, por meio da audiência de instrução e julgamento.

d) Fase Decisória: caracteriza-se pelo ato no qual o juiz profere a sentença no processo penal.

e) Fase Recursal: momento em acusação e defesa podem interpor o respectivo recurso dirigido ao órgão do Poder Judiciário competente para julgálo.

f) Fase executória: é caracterizada por dar início ao cumprimento de pena pelo condenado, após o trânsito em julgado da sentença penal condenatória.

Outra observação necessária diz respeito à característica marcante, tanto do processo como do procedimento, sobre a necessidade de os atos processuais serem desenvolvidos em uma sequência, como um caminhar, sempre em progresso. A característica do processo ou procedimento de caminhar para frente, de marcha, deve ser observada também no Procedimento Comum Ordinário. Isso 
auxilia na compreensão dos superframes elaborados, pois os frames do Direito Processual Penal retratam a sequência temporal de atos processuais.

A exemplo disso, o superframe que abordamos a seguir o da Fase Acusatória. Esse grande frame, que abarca eventos menores, inicia-se com a denúncia, que é encaminhada ao juiz, o qual pode agir de duas formas: a primeira consiste em receber a denúncia e determinar a citação do réu (anteriormente denominado de denunciado) para apresentar defesa prévia. A segunda concerne à rejeição da denúncia e à determinação do arquivamento tanto da denúncia quanto do inquérito policial, formado pelos documentos que a acompanham. Se a denúncia for recebida, o juiz determina a citação do réu para apresentar defesa. Após a apresentação da defesa, o juiz decide novamente se determina o prosseguimento do processo ou se absolve sumariamente o réu - ou seja, se o absolve sem apreciação das demais provas. No caso da primeira hipótese, o juiz convoca as partes para uma audiência de instrução e julgamento, momento que inicia a Fase Instrutória.

A figura a seguir ilustra o superframe Fase Acusatória, indicando os frames que a compõem e as relações que se estabelecem entre tais eventos. No caso do frame Oferecimento de Denúncia, apontamos os possíveis evocadores elencados após o estudo do domínio e as primeiras consultas ao corpus de apoio: trata-se das unidades denúncia e denunciar.

$\mathrm{Na}$ Figura 2, esquematizamos as relações frame a frame que evidenciam a dinâmica dos eventos jurídicos no âmbito da Fase Acusatória. Por exemplo, como indica o mapa, o representante do Ministério Público tem a possibilidade de proceder com o Oferecimento de denúncia em face do acusado - evento que inicia essa fase do processo. Em seguida, há a possibilidade de Aditamento da denúncia oferecida. Desse modo, o aditamento é um possível subframe de Oferecimento de denúncia, pois a denúncia aditada pode conter a parte que foi modificada na denúncia original. Além disso, o subframe Oferecimento de denúncia precede 0 $\underline{\text { Recebimento da denúncia ou a Rejeição da denúncia, }}$

Figura 2 - O superframe Fase Acusatória

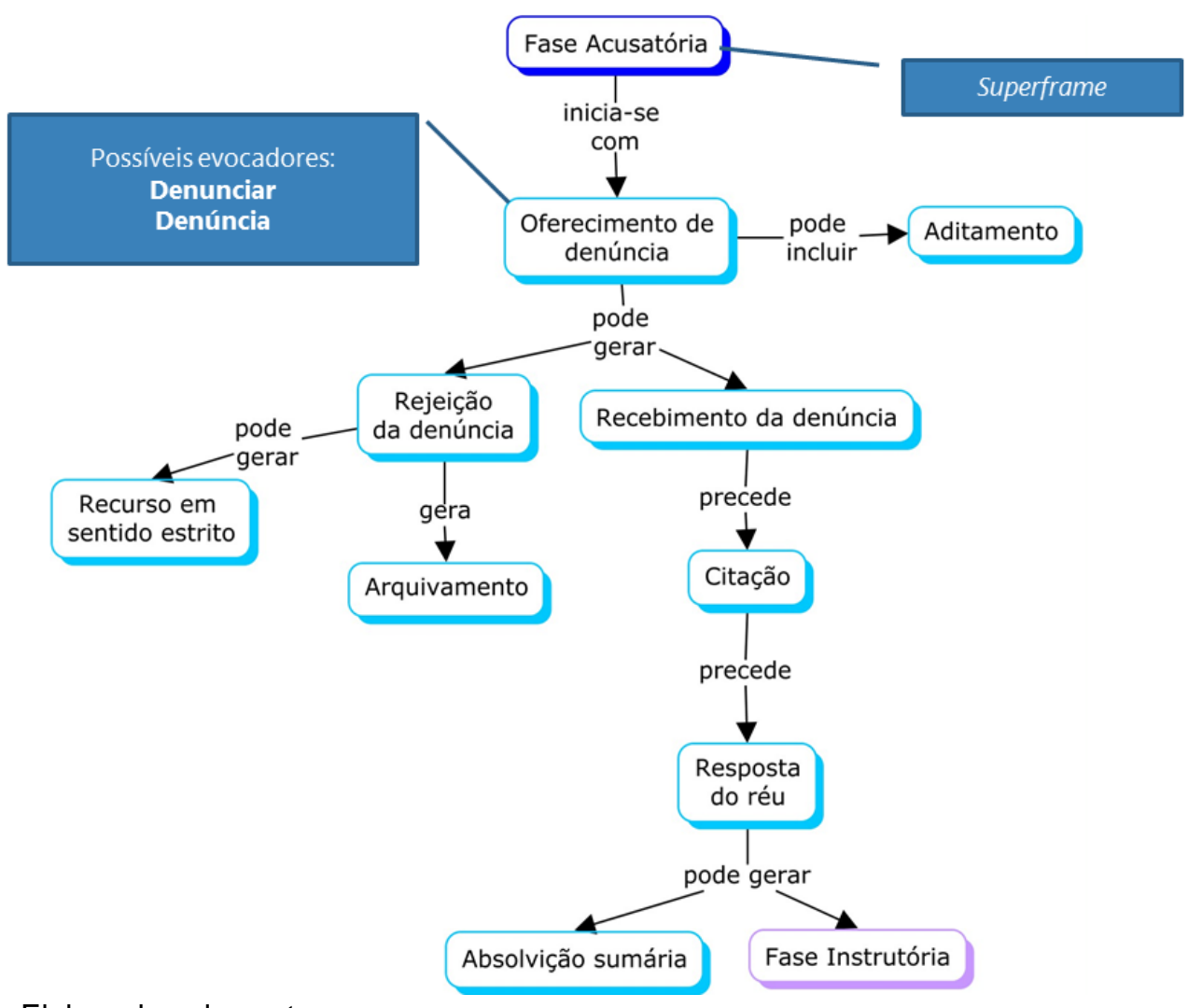

Fonte: Elaborada pelos autores. 
ou seja, o juiz a recebe ou a rejeita, existindo, portanto, relação de alternância/exclusão. Se o juiz aceitar a denúncia, abre-se a possibilidade da $\underline{\text { Resposta do réu, e se inicia o superframe Fase }}$ instrutória.

Dessa forma, o superframe Fase acusatória é marcado pelo oferecimento da denúncia pelo representante do Ministério Público. Isso motivou a escolha da palavra denunciar para a análise inicial de concordâncias no Sketch Engine, conforme figura 3.
Como exibe a Figura 3, os exemplos com denunciar no corpus foram escassos, indicando que 0 evocador elencado provavelmente não era o mais frequente no contexto desse frame. Assim, dando continuidade à exploração dos evocadores de frame de Oferecimento de denúncia, observamos as ocorrências da palavra denúncia no Concordanciador e no recurso Word Sketch, que exibe todas as combinatórias sintáticas do termo buscado. Nesse contexto, a figura a seguir destaca a recorrência da unidade lexical oferecer denúncia, que se constitui no principal evocador do frame em tela (Figura 4).

Figura 3 - Análise da palavra denunciar no concordanciador do Sketch Engine

delitiva, o MINISTÉRIO PÚBLICO FEDERAL denuncia SILMAR SIDINEI STABILE,MOACIR BATISTELA, Ante o exposto, o MINISTÉRIO PÚBLICO FEDERAL denuncia VICENTE APARECIDO DAMASCENO e ELIZABETH MARIA praticados $\mathrm{O}$ Ministério Público Federal denunciou os réus pela prática dos delitos de falsidade

Fonte: Elaborada pelos autores.

O exemplo (1), a seguir, foi extraído a partir da inserção da palavra denunciar na aba Concordância. Essa sentença exemplifica o subframe Oferecimento de denúncia. Nesse contexto, o representante do Ministério Público é o responsável por denunciar os investigados, também assinalados como elementos de frame (EFs):

(1) tendo em vista a presença da materialidade e da autoria da conduta delitiva, o [MINISTÉRIO PÚBLICO FEDERAL EF Denunciante] denuncia [Silmar Sidinei Stabile, Moacir Batistela, Geferson Marcilon Marques e Jesana Pereira da silva pela prática EF Denunciado].

Figura 4 - Unidade lexical oferecer denúncia

Word Sketch - combinatórias

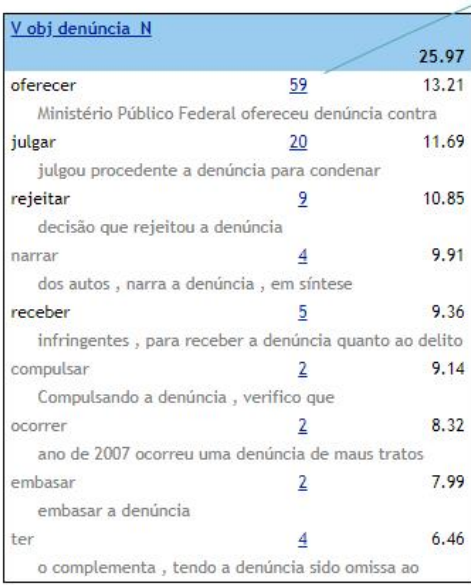

Fonte: Elaborada pelos autores.
A partir de tais buscas no corpus de estudo, chegamos à seguinte sistematização do frame Oferecimento de denúncia, com os respectivos elementos de frame assinalados entre parênteses (Figura 5). Na Figura 6, exibimos a estrutura da descrição desse frame que comporá o Dicionário de Cenários Jurídicos, a qual inclui os seguintes elementos: a) glosa do frame, elaborada com base nos elementos verificados por meio de análise de corpus; b) evocadores do frame; c) elementos de frame; e d) as respectivas relações. Considerando a 
necessidade de adaptação da terminologia ao público semileigo, as seções serão denominadas, respectivamente: a) descrição do cenário; b) palavras do cenário; c) elementos do cenário; e d) relacionamentos. Como indica a figura, as relações entre frames refletem a estruturação dos mapas conceituais baseados no estudo do domínio e no corpus de apoio.

Figura 5 - Sistematização do frame Oferecimento de denúncia

\section{Frame Oferecimento_de_Denúncia (superframe Fase Acusatória)}

Evocadores : oferecer denúncia, denúncia, denunciar Elementos de frame: denunciante, denunciado, infração

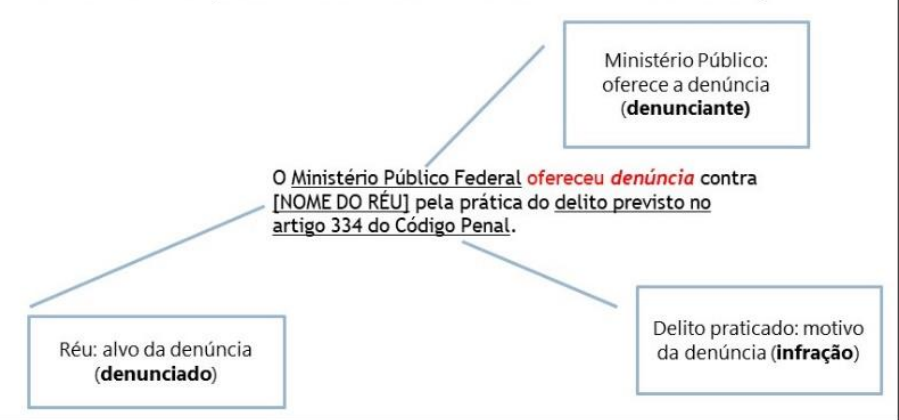

Fonte: Elaborada pelos autores.

Figura 6 - Estrutura da descrição do frame Oferecimento de denúncia para o Dicionário de Cenários Jurídicos

\section{Oferecimento de Denúncia}

Descrição do cenário:

Em um processo penal comum ordinário, a denúncia é oferecida pelo Ministério Público (MP), o qual acusa o suposto autor do ato ilícito, apresentando os fatos que fundamentem a acusação. A denúncia deve conter a indicação de provas relativas ao crime, bem como a lei penal que deve ser aplicada. 0 ato é materializado na peça processual ho-
mônima, que inicia a ação penal. após o MP oferecer a denúncia, o juiz irá decidir se ela deverá ser recebida ou mojnima, queitada.

Palavras do cenário: oferecer denúncia, denúncia, denunciar

Elementos do cenário: denunciante, denunciado, infração

Relacionamentos: pode gerar Recebimento da denúncia ou Reieição da denúncia

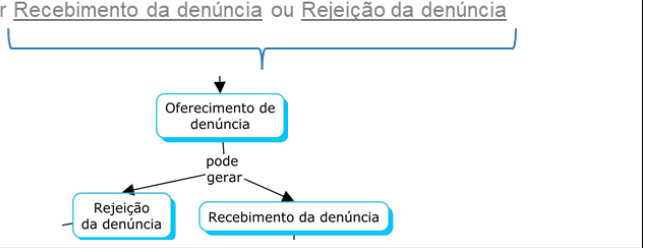

artigo pertence à Fase Recursal (Figura 7). Como ilustra o mapa, a Publicação de sentença precede e pode gerar a Recurso. Após o trânsito em julgado da sentença ou acórdão, pode-se iniciar a Fase Executória. O frame da Fase Recursal destacado a seguir é o de Recurso, para o qual elencamos, a partir do estudo do domínio, a unidade lexical recorrer como ponto de partida para o estudo de corpus.

Figura 7 - O superframe Fase Recursal

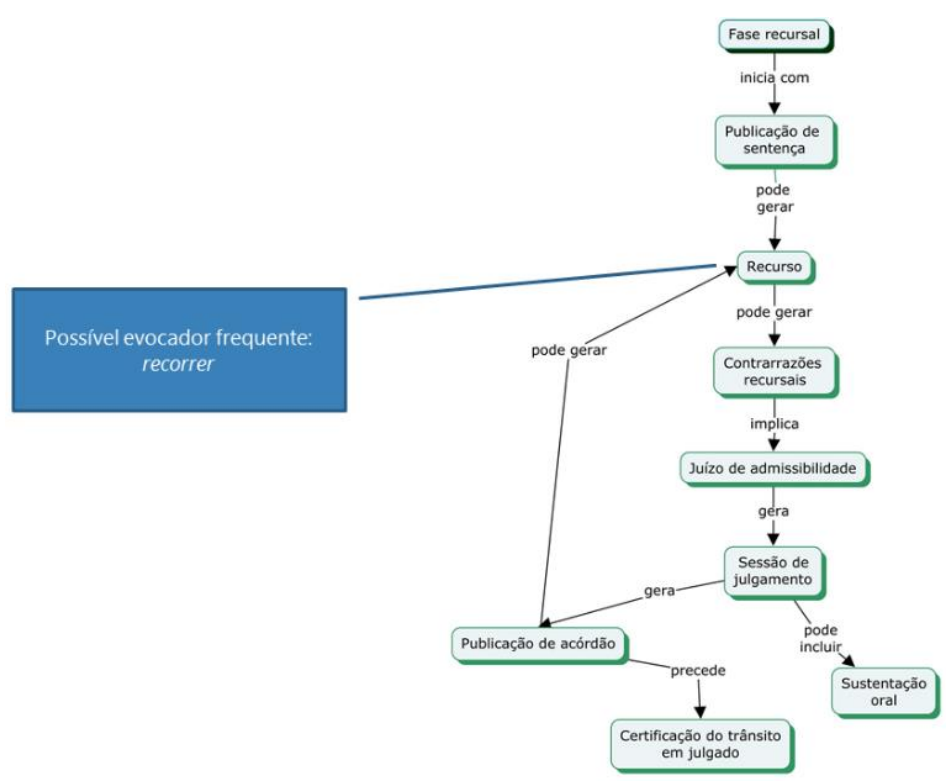

Fonte: Elaborada pelos autores.

Conforme as etapas anteriores, seguimos 0 passo a passo da análise anteriormente descrita e fizemos a busca no Word Sketch com o evocador recorrer, extraído durante o processo de estudo do domínio. Posteriormente, na aba Concordância, buscamos exemplos concernentes a essa unidade lexical e obtivemos os resultados descritos na Figura 8.

Fonte: Elaborada pelos autores.

No intuito de abordar um caso em que foi necessário redirecionar os procedimentos metodológicos, tendo em vista os resultados encontrados, o segundo frame que exploramos neste 
Figura 8 - Resultado da pesquisa da palavra recorrer na aba Concordância

não assumam tamanha gravidade, devese recorrer , tanto quanto possível, ao emprego da analogia , não assumam tamanha gravidade, devese recorrer na medida do possivel ao emprego da analogia em não assumam tamanha gravidade, devese recorrer , tanto quanto possivel, ao emprego da analogia , não assumam tamanha gravidade, devese recorrer na medida do possivel ao emprego da analogia em , contradição ou obscuridade no acórdão recorrido, sob o fundamento de que cabe à autora a INEXISTÊNCIA. I Pelo exame do acórdão recorrido remanesce evidente não restarem omissos os . INEXISTÊNCIA. I Pelo exame do acórdão recorrido remanesce evidente não restarem omissos os - INEXISTÊNCIA. I Pelo exame do acórdão recorrido remanesce evidente não restarem omissos os contradição ou obscuridade no acórdão recorrido , sob o fundamento de que o percentual de INEXISTÊNCIA. I Pelo exame do acórdão recorrido remanesce evidente não restarem omissos os , contradição ou obscuridade no acórdão recorrido , sob o fundamento de que há omissão no julgado INEXISTÊNCIA. I Pelo exame do acórdão recorrido remanesce evidente não restarem omissos os

ILVA, objetivando sanar omissões no acórdão recorrido. A Autarquia Previdenciária alega que ocorreu , contradição ou obscuridade no acórdão recorrido , sob o fundamento de que a decadência incide ao INEXISTÊNCIA. I Pelo exame do acórdão recorrido remanesce evidente não restarem omissos os sanar omissões ou contradições no acórdão recorrido, objetivando a reforma do julgado para fixar os INEXISTÊNCIA. I Pelo exame do acórdão recorrido remanesce evidente não restarem omissos os sera da conclusão do julgamento. 0 acórdão recorrido assentou como fundamento o entendimento "de , contradições ou obscuridades no acórdão recorrido . Autarquia alegou que o acórdão determinou a . INEXISTÊNCIA. I Pelo exame do acórdão recorrido remanesce evidente não restarem omissos os

Fonte: Elaborada pelos autores.

Nesse âmbito, extraímos um exemplo com a palavra recorrer, reproduzido a seguir:

(2) A [defesa recorrente] recorreu alegando a impossibilidade de se manter a condenação pecuniária advinda da sanção originária do delito com a pena.

O resultado da busca exposta na Figura 8 não foi satisfatório para trazer exemplos desse frame, pois, após excluirmos os resultados repetidos ou não relacionados a julgamentos de casos criminais, restaram poucos exemplos.

Assim, verificamos a necessidade de retornar ao corpus de apoio e constatamos que os textos que tratavam dos recursos, ato processual praticado eminentemente na fase recursal, faziam também referência ao verbo interpor. Citamos como exemplo Rangel (2017), o qual apresenta os seguintes empregos para a palavra interpor em sua obra seguem exemplos abaixo:

(3) Outra questão quanto à sentença de absolvição sumária é a possibilidade de o [ofendido recorrente], habilitado ou não como assistente de [acusação recorrido], interpor recurso dessa decisão que o impede de obter um decreto condenatório e, consequentemente, um título executivo judicial.

(4) Ora, claro nos parece que o legislador legitimou extraordinariamente o [ofendido recorrente] para interpor recurso, sempre que o [Ministério Público recorrido] não o fizer, prejudicando, assim, seu interesse em, tendo um título executivo judicial nas mãos, obter 0 ressarcimento dos prejuízos sofridos com a conduta do [autor recorrente] do, em tese, fatocrime.

(5) À [Defensoria Pública recorrente] do Estado caberá interpor recursos aos Tribunais Superiores, quando cabíveis.

Assim, inserimos a palavra interpor na ferramenta Word Sketch como possível evocadora de frames da Fase_recursal e obtivemos os resultados ilustrados na Figura 9.

A Figura 9 demonstra que a pesquisa da palavra interpor foi mais frutífera, pois exibiu mais exemplos relativos à Fase Recursal, expostos a seguir. Tais sentenças indicam que o evocador interpor é mais frequente que recorrer nesse

Figura 9 - Unidade lexical interpor recurso

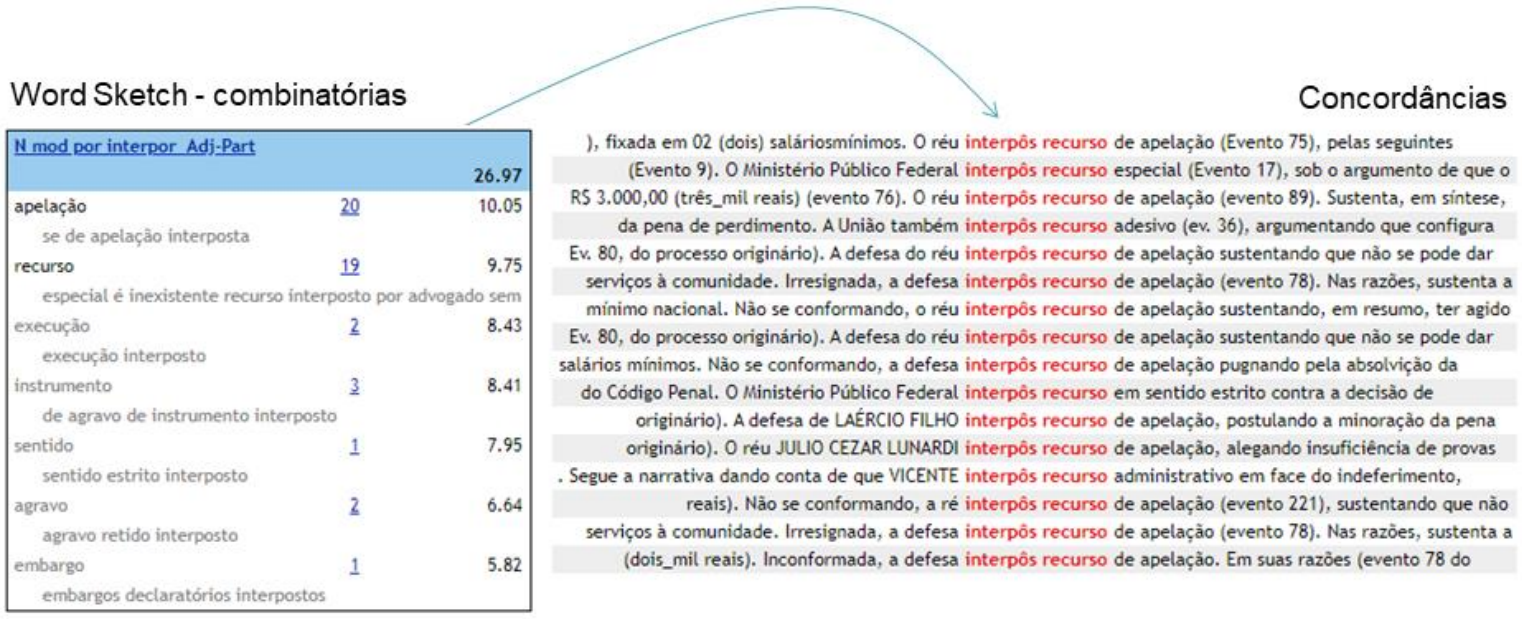

Fonte: Elaborada pelos autores. 
contexto:

(6) $\mathrm{O}$ [réu recorrente] interpôs recurso de apelação (Evento 75), pelas seguintes razões: [(a) absolvição por erro sobre elemento do tipo, pois não... justificativa]

(7) $\mathrm{O}$ [réu recorrente] interpôs apelação afirmando o seguinte: [(a) a conduta é materialmente atípica em razão da aplicação do princípio da... justificativa]

(8) Contra essa decisão o [Ministério Público Federal recorrente] interpõe recurso em sentido estrito.

(9) A [defesa recorrente] do réu interpôs recurso de apelação [sustentando que não se pode dar crédito à versão da única testemunha arrolada pela acusação, pois o... justificativa]

A partir de tais buscas no corpus de estudo, chegamos à seguinte sistematização do frame Recurso, com os respectivos elementos de frame assinalados entre parênteses (Figura 10).

Figura 10 - Sistematização do frame Recurso

\section{Sistematização do frame Recurso (superframe Fase_Recursal)}

Evocadores: interpor recurso, recorrer

Elementos de frame: recorrente, recorrido, justificativa

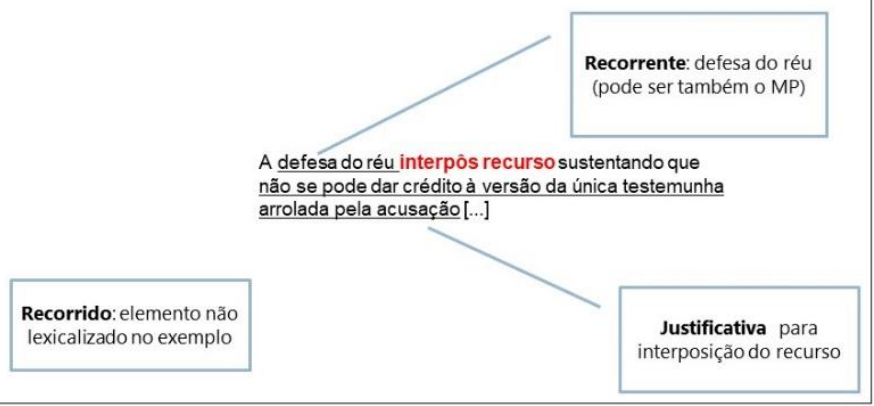

Fonte: Elaborada pelos autores.

De modo geral, os exemplos elencados nesta seção indicam que a metodologia de trabalho com corpora de estudo e de apoio nem sempre se estabelece de forma linear, dado que ambos os materiais são complementares. Nesse sentido, constatamos que determinados frames podem exigir consultas integradas a ambos os corpora, em diferentes etapas do percurso analítico.

\section{Considerações Finais}

O presente artigo teve como objetivo a delinear a proposta metodológica que embasa a construção do Dicionário de Cenários Jurídicos, um recurso lexicográfico em construção, voltado ao público semileigo. Nesse percurso, abordamos a relevância da Semântica de Frames para uma abordagem mais contextualizada da linguagem jurídica e a necessidade do estabelecimento de uma metodologia que integre consultas aos diferentes corpora compilados. Isso permite uma relação simbiótica entre as contrapartes quali e quantitativa do trabalho, visto que o processo de pesquisa e confirmação das unidades lexicais do domínio investigado, em alguns casos, pode demandar buscas que integrem consultas simultâneas ao corpus de estudo e ao corpus de apoio.

Além disso, dada a complexidade da linguagem jurídica, salientamos a relevância de um trabalho interdisciplinar que envolva o olhar de linguistas e de especialistas em Direito, com vistas a construir um recurso pertinente ao público-alvo. Nesse âmbito, entendemos que a Semântica de Frames pode contribuir para uma melhor compreensão da dinâmica de eventos e participantes do Direito - no caso dos exemplos analisados, exploramos a subárea do Direito Processual Penal -, pois a teoria é pertinente não só à identificação e à descrição de tais elementos, mas também à organização dos participantes e eventos em cada uma das fases que constituem a dinâmica dos atos e procedimentos jurídicos.

Por fim, como etapas futuras do projeto, destacamos a consolidação da estrutura de acesso do Dicionário de Cenários Jurídicos, bem como a finalização da descrição dos demais frames que compõem cada uma das fases processuais do Direito Processual Penal. A partir dos resultados encontrados ao término dessa etapa, o projeto dará início à exploração dos frames atinentes às demais áreas que compõem o Direito Brasileiro. 


\section{Referências}

ALUÍSIO, Sandra Maria; ALMEIDA, Gladis Maria de Barcellos. O que é e como se constrói um corpus? Lições aprendidas na compilação de vários corpora para pesquisa linguística. Calidoscópio, São Leopoldo, v. 4, n. 3, p. 156-178, set./dez. 2006. Disponível em: <revistas.unisinos.br/index.p hp/calidoscopio/article/view/6002/3178>. Acesso em: 01 set. 2019.

ATKINS, Sue; RUNDELL, Michael; SATO, Hiroaki. The contribution of FrameNet to Practical Lexicography. International Journal of Lexicography, Oxford, v. 16, n. 3, p. 333-357, 2003.

CHISHMAN, Rove. Convergências entre Semântica de Frames e Lexicografia. Linguagem em (Dis)curso, Tubarão, v. 16, p. 547-559, set./dez. 2016.

FILLMORE, Charles. Frame Semantics. In: The Linguistics Society of Korea. Linguistics in the Morning Calm. Seoul: Hansinh Publishing Co., 1982. p. 111-137.

FILLMORE, Charles. Frames and the semantics of understanding. Quaderni di Semantica, v. 6, n. 2, p. 222-254, 1985.

FILLMORE, Charles. Frame semantics and the nature of language. Annals of the New York Academy of Sciences: Conference on the Origin and Development of Language and Speech, v. 280, p. 20-32, 1976.

FILLMORE, Charles; BAKER, Collin. A frames approach to semantic analysis. In: HEINE, Bernd; NARROG, Heiko (Eds.). The Oxford Handbook of Linguistic Analysis. New York: Oxford University Press, 2010. p. 313-339.

GEERAERTS, Dirk. Introduction: A rough guide to Cognitive Linguistics. In: GEERAERTS, Dirk. (Ed.). Cognitive Linguistics: Basic Readings. Berlin: Mouton de Gruyter, 2006. p. 1-28.

JOHNSON, Mark. The body in the mind. The bodily basis of meaning, imagination, and reason. Chicago: The University of Chicago Press, 1987.

KÖVECSES, Zoltán. Language, mind and culture. A practical introduction. New York: Oxford University Press, 2006.

LANGACKER, R. W. Cognitive Grammar. Introduction to Concept, Image, and Symbol. In: Geeraerts, D. (Ed.) Cognitive Linguistics: basic readings. Berlin/New York: Mouton de Gruyter, 2006.
LANGACKER, R. W. Cognitive Grammar: a basic introduction. New York: Oxford University Press, 2008.

MINGHELLI, Thais Domênica. Eventos legais e a sua descrição conforme a semântica de Frames. 2016. 173f. Tese (Doutorado em Linguística Aplicada) Programa de Pós-Graduação em Linguística Aplicada. Universidade do Vale do Rio dos Sinos, São Leopoldo, 2016. Disponível em: $<\mathrm{h}$ ttp://www.repositorio.jesuita.org.br/handle/UNISIN OS/5185>. Acesso em: 11 out. 2019.

MIRANDA, N. S. O caráter partilhado da construção da significação. Veredas: Revista de Estudos Linguísticos, Juiz de Fora, v. 5, n. 1, p. 57-81, 2001. Disponível em: <http://www.ufjf.br/revistaveredas/files/2009/12/arti go49.pdf>. Acesso em: 08 dez. 2017.

MULLER, Carolina. Princípios Metodológicos para a construção de uma ontologia Baseada da Semântica de Frames. Tese (Doutorado em Linguística Aplicada). Programa de Pós-Graduação em Linguística Aplicada. Universidade do Vale do Rio

dos Sinos, São Leopoldo, 2015. Disponível em: <ht tp://www.repositorio.jesuita.org.br/bitstream/handle/ UNISINOS/4931/Carolina\%20M\%C3\%BCller_.pdf? sequence $=1$ \&isAllowed $=y>$. Acesso em: 11 out. 2019.

PIMENTEL, Janine. Criteria for the Validation of Specialized Verb Equivalents: Applications in Bilingual Terminography. Thesis (PhD in Translation) - Faculté des Études Supérieures, Université de Montréal, Montreal, 2012.

RANGEL, Paulo. Direito processual penal. 25. ed. rev. e atual. Atualizada de acordo com o Novo CPC e com a Lei 13.256, de 04.02.2016. São Paulo: Atlas, 2017.

RODRIGUES, Fernando José Amâncio. O Direito Processual Penal Brasileiro segundo a teoria da Semântica de Frames: os sujeitos processuais. 2019. 143 f. Dissertação (Mestrado em Linguística Aplicada) - Programa de Pós-Graduação em Linguística Aplicada, Universidade do Vale do Rio dos Sinos, São Leopoldo, 2019.

$\mathrm{ROSCH}, \mathrm{E}$. Natural categories. Cognitive Psychology, [s.I.], v. 4, n. 3, p. 328-350, 1973.

SALOMÃO, Margarida. Teorias da linguagem: a perspectiva sociocognitiva. FÓRUM DE LINGUAGEM, 2., Rio de Janeiro. Anais... Rio de Janeiro: Universidade Federal do Rio de Janeiro, 2006. p. 1-13. 


\section{COMO CITAR ESSE ARTIGO}

CHISHMAN, Rove et al. Frames semânticos como organizadores do léxico do Direito Processual Penal: uma proposta metodológica. Signo, Santa Cruz do Sul, v. 45, n. 82, jan. 2020. ISSN 1982-2014. Disponível em: <https://online.unisc.br/seer/index.php/signo/article/view/14338>. em: doi:https://doi.org/10.17058/signo.v45i82.14338. 